\title{
Exocrine and Endocrine Pancreatic Cancer pTX TNM Finding v7
}

National Cancer Institute

\section{Source}

National Cancer Institute. EXocrine and Endocrine Pancreatic Cancer PTX TNM Finding

v7. NCl Thesaurus. Code C90287.

Exocrine or endocrine pancreatic cancer in which the primary tumor cannot be assessed.

(from AJCC 7th Ed.) 